\title{
Novel Therapeutic Targets in Cutaneous Squamous Cell Carcinoma
}

\author{
Teruki Yanagi*, Shinya Kitamura and Hiroo Hata \\ Department of Dermatology, Hokkaido University Graduate School of Medicine, Sapporo, Japan
}

Cutaneous squamous cell carcinoma (SCC) is one of the common cancers in Caucasians, accounting for $20-30 \%$ of cutaneous malignancies. The risk of metastasis is low in most patients; however, aggressive SCC is associated with very high mortality and morbidity. Although cutaneous SCC can be treated with surgical removal, radiation and chemotherapy singly or in combination, the prognosis of patients with metastatic SCC is poor. Recently, the usage of immune checkpoint blockades has come under consideration. To develop effective therapies that are less toxic than existing ones, it is crucial to achieve a detailed characterization of the molecular mechanisms that are involved in cutaneous SCC pathogenesis and to identify new drug targets. Recent

OPEN ACCESS

Edited by:

Atsushi Otsuka,

Kyoto University, Japan

Reviewed by:

Tatsuya Takenouchi,

Niigata Cancer Center

Hospital, Japan

Hiroshi Kato,

Nagoya City University, Japan

*Correspondence: Teruki Yanagi

yanagi@med.hokudai.ac.jp

Specialty section:

This article was submitted to Cancer Immunity and Immunotherapy,

a section of the journal

Frontiers in Oncology

Received: 21 December 2017 Accepted: 08 March 2018

Published: 23 March 2018

Citation:

Yanagi T, Kitamura S and Hata H (2018) Novel Therapeutic Targets in Cutaneous Squamous

Cell Carcinoma.

Front. Oncol. 8:79.

doi: 10.3389/fonc.2018.00079 studies have identified novel molecules that are associated with SCC carcinogenesis and progression. This review focuses on recent advances in molecular studies involving SCC tumor development, as well as in new therapeutics that have become available to clinicians.

Keywords: cyclin-dependent kinase, mitochondria, Drp1, PD-1 antibody, epidermal growth factor receptor

\section{INTRODUCTION}

In light of today's demographic aging, skin cancer is becoming more prevalent. Cutaneous squamous cell carcinoma (SCC) is one of the most common cancers in Caucasian populations, and its prevalence is increasing (1). Cutaneous SCC accounts for $20-30 \%$ of cutaneous malignancies $(2,3)$. The risk of metastasis is low in most patients (2); however, aggressive SCC is associated with high morbidity and mortality (4). Although cutaneous SCC can be treated with surgery, radiation, and chemotherapy singly, or in combination, the prognosis of patients with metastatic SCC is almost always poor $(3,5)$. Today, chemotherapy with cisplatin alone or combined with 5 -FU is being conducted with positive responses (6-9). However, the National Comprehensive Cancer Network Guidelines describe the evidence regarding systemic therapies for distant metastatic cutaneous SCC as limited. Recently, clinical trials on epidermal growth factor receptor (EGFR) inhibitors and immune checkpoint blockers have shown promising results as treatments for SCC (10-12). This review focuses on recent advances in molecular studies related to SCC tumor development and on new therapeutics that have become available.

\section{RECENT PROGRESS IN CUTANEOUS SCC THERAPEUTICS}

\section{Novel Targeted Therapies}

Cutaneous SCC overexpresses EGFR; thus, EGFR is a promising target for therapies. Cetuximab, an EGFR inhibitor, has been administered to cutaneous SCC patients. In some phase II studies, 
there have been good responses to cetuximab in patients with locally advanced or regional SCC types (10, 13-15). However, in distant metastatic diseases, it has been reported as ineffective. Also, tyrosine kinase inhibitors have been used to disrupt EGFR pathways. Case reports on gefetinib and imatinib have described slightly positive responses in cutaneous SCC patients $(16,17)$. Also, a single-arm phase II clinical trial has shown gefetinib to demonstrate modest antitumor activity in metastatic or locoregionally recurrent cutaneous SCC, with limited adverse events (18). Furthermore, bortezomib, a selective inhibitor of the $26 \mathrm{~S}$ proteasome, may have antitumor effects in cutaneous SCC, although the mechanisms have not been clarified (19).

\section{Biological Modifiers}

30 years ago, isotretinoin was reported to have efficacy as a treatment for local advanced cutaneous SCC alone or in combination. Interferons have also been used for local cutaneous SCC. A phase II study on bio-chemotherapy with interferons, retinoids, and cisplatin showed a positive response in $67 \%$ of locally advanced SCC cases (20). However, the efficacy against metastatic cases remains unclear.

\section{Cytotoxic Chemotherapy}

Regrettably, recent advances in cytotoxic chemotherapy have been limited. Capecitabine, an oral prodrug of 5-FU, has been used to treat cutaneous SCC (21). In head and neck SCC cases, intra-arterial chemotherapy has been conducted as a neoadjuvant therapy (22). To date, in cutaneous SCC, no obvious evidence for positive responses has been reported, even though some cases have been described in limited detail (23).

\section{Immune Checkpoint Inhibitors}

Recently, the US FDA approved PD-1 inhibitors (immune checkpoint inhibitors) for head and neck SCCs with continued progression during or after platinum chemotherapy $(24,25)$. For cutaneous SCC, several case reports have shown immune checkpoint inhibitors to have promising results. Patients with advanced cutaneous SCC responded to anti-PD-1 (nivolumab and pembrolizumab), and anti-CTLA-4 (ipilimumab) agents (26-29).

\section{Radiation With Chemotherapies or Immunotherapies}

Platinum-based chemotherapy has been combined with local radiation. Cisplatin-based chemotherapy combined with concurrent radiation showed better results than cisplatin only $(13,30)$. Neoadjuvant chemotherapies before radiation were also reported to have promising results (31). Recently, the abscopal effect during radiation therapy after the administration of immune checkpoint inhibitors has been spotlighted. This effect is a phenomenon in which local radiotherapy is associated with the regression of metastatic cancer at a distance from the irradiated site (32). To date, abscopal effects have been observed in melanoma patients but not in cutaneous SCC. It is not clear whether these effects will occur in cutaneous SCCs; however, combined therapies of immune checkpoint inhibitors and radiation might have a synergistic effect.

\section{Other Candidates \\ Human Papilloma Virus (HPV) in Cancer Cells}

Until recently, the role of HPV in cutaneous SCC was not well defined. However, a meta-analysis has found evidence that HPV is associated with cutaneous SCC (33). This systematic review indicated that cutaneous SCC harbors HPV more than normal skin does. Furthermore, an increase in HPV prevalence has been observed in SCC tumors from immunosuppressive patients. A study using an animal model showed that the interaction between UVB and HPV infection strongly promotes the development of cutaneous SCC (34). Furthermore, several targeted therapies for HPV-associated head and neck SCC have been tried (35); thus, HPV might be a promising target for cutaneous SCC as well.

\section{MicroRNAs (miRs) in Cancer Cells}

MicroRNAs are short, non-coding RNAs that suppress the expression of target genes. miRs can regulate various gene targets, and they play a crucial role in biological mechanisms (36). Certain miRs are associated with the onset and progression of cancers, suggesting that miRs could be targets for cancer therapies. In cutaneous SCC, several miRs are reported to be overexpressed or downregulated (36). miR-21 and miR-31 are upregulated in cutaneous SCC. The targets of these miRs are PDCD4/GRHL3/PTEN and RhoTBT1, respectively $(36,37)$. To inhibit the undesirable effects of up-regulated miRs, the administration of complementary nucleic acids might be a potential cancer therapy. By contrast, miR-1, miR-34a, and miR-124 are downregulated in cutaneous SCC (36). These miRs target important molecules of cell proliferation, which tend to be activated in cancer cells. Thus, promoting the over-expression of these miRs could be an option for cancer therapies. Furthermore, various miR delivery systems have been developed. Cheng et al. reported on pHLIP-mediated miR delivery methods, in which miRs could be transported across plasma membranes under the acidic conditions found in solid tumors (38). As such, miRs are also promising targets for cutaneous SCC as well as other tumors.

\section{Cyclin-Dependent Kinase (Cdk) 16 in Cancer Cells}

Recently, Cdk4/Cdk6 inhibitor (palbociclib) showed promising results for metastatic breast cancer $(39,40)$. Some Cdks are overexpressed in cutaneous SCC; thus, Cdk inhibitors may become a novel therapy option. Among Cdks, we have focused on cyclin-dependent kinase 16 (Cdk16) (also known as PCTK1, PCTAIRE1) and investigated its molecular functions. Cdk16 is a member of the Cdk family (41). Molecular functions for CDK16 are reported to vesicular transport (42) and spermatogenesis (43).

To investigate the role of Cdk16 in cancerous cells, we performed gene-knockdown experiments targeting Cdk16 (44-47). In cell lines of cutaneous SCC, prostate cancer, breast cancer, cervical cancer, and melanoma, knockdown of $C d k 16$ inhibited cancer cell proliferation, and induced apoptosis over 
time. But, no role for Cdk16 was observed in the proliferation of non-transformed cells (IMR-90 and HaCaT cells). To identify target molecules of Cdk16, we performed yeast two-hybrid screens with human Cdk16 protein as bait. We identified tumor suppressor p27 as a Cdk16 interactor and demonstrated that Cdk16 phosphorylates p27 at Ser10 by in vitro kinase assays (46). The knockdown of Cdk16 modulated p27 (Ser10) phosphorylation, leading to p27 accumulation in cancerous cells. In tumor xenografts of cutaneous SCC cells, the inducible conditional knockdown of Cdk16 suppressed tumor growth (47).

To evaluate the clinical importance of Cdk16, we also studied primary tumor samples In primary tumors from the patients with breast, prostate, cutaneous basal, or SCCs, Cdk16 was expressed more highly in cancer lesions than in normal tissues (46-48). In prostate cancers, a comparison of Cdk16 immunostaining with Gleason grade revealed lower expression levels in well-differentiated tumors than in less- differentiated tumors (46). In breast cancers, Cdk16 expression was elevated in in situ carcinomas and invasive cancers relative to the expression in normal mammary epithelium. The significantly higher levels of Cdk16 protein that are seen in invasive cancers are associated with higher histologic grades (46). Moreover, we showed that gene knockdown of $C d k 16$ sensitizes cancer cells to TNF-family cytokines, such as Fas-ligand and TNF-related apoptosisinducing ligand (49).

To advance in vitro results on Cdk16 silencing, we investigated the in vivo therapeutic potential by using siRNA encapsulated with lipid nanoparticles (LNP) (50). Therapy of Cdk16 siRNA was performed using colorectal cancer HCT116 cells and melanoma A2058 cells. Treatment with Cdk16 siRNALNP reduced tumor volume and weight significantly. TUNEL staining showed increased apoptosis of cancer cells treated with Cdk16 siRNA.

These findings show an expected role for Cdk16 in regulating p27 expression and tumor proliferation (Figure 1). We observed these functions for Cdk16 in various cancer cells (cutaneous SCCs; basal cell carcinomas; prostate, breast, and cervical cancers; and melanomas). This implies that the p27 regulation by Cdk16 is a common machinery in human cancers.

\section{Dynamin-Related Protein 1 (Drp1) in Cancer Cells}

We have also focused on the mitochondria-associated molecule Drp1 (51). Drp1 regulates mitochondrial fission. Recently, it was found to be associated with cancer cell proliferation in melanoma and lung cancer $(52,53)$. Disrupted mitochondrial networks induce cell cycle arrest and apoptosis $(53,54)$. Also, Drp1 has been reported as a prognostic factor in several malignancies, such as lung adenocarcinomas and glioblastomas $(55,56)$. Based on these previous studies, we investigated the role of Drp1 in cutaneous SCCs. Drp1 gene-knockdown SCC cells showed lower cell proliferation than control cells, as assessed by cell counting and clonogenic assays. DNA content Cell Cycle analysis showed Drp1 knockdown to cause G2/M phase arrest. Morphologically, the depletion of Drp1 resulted in an elongated mitochondrial network. The MEK inhibitor,
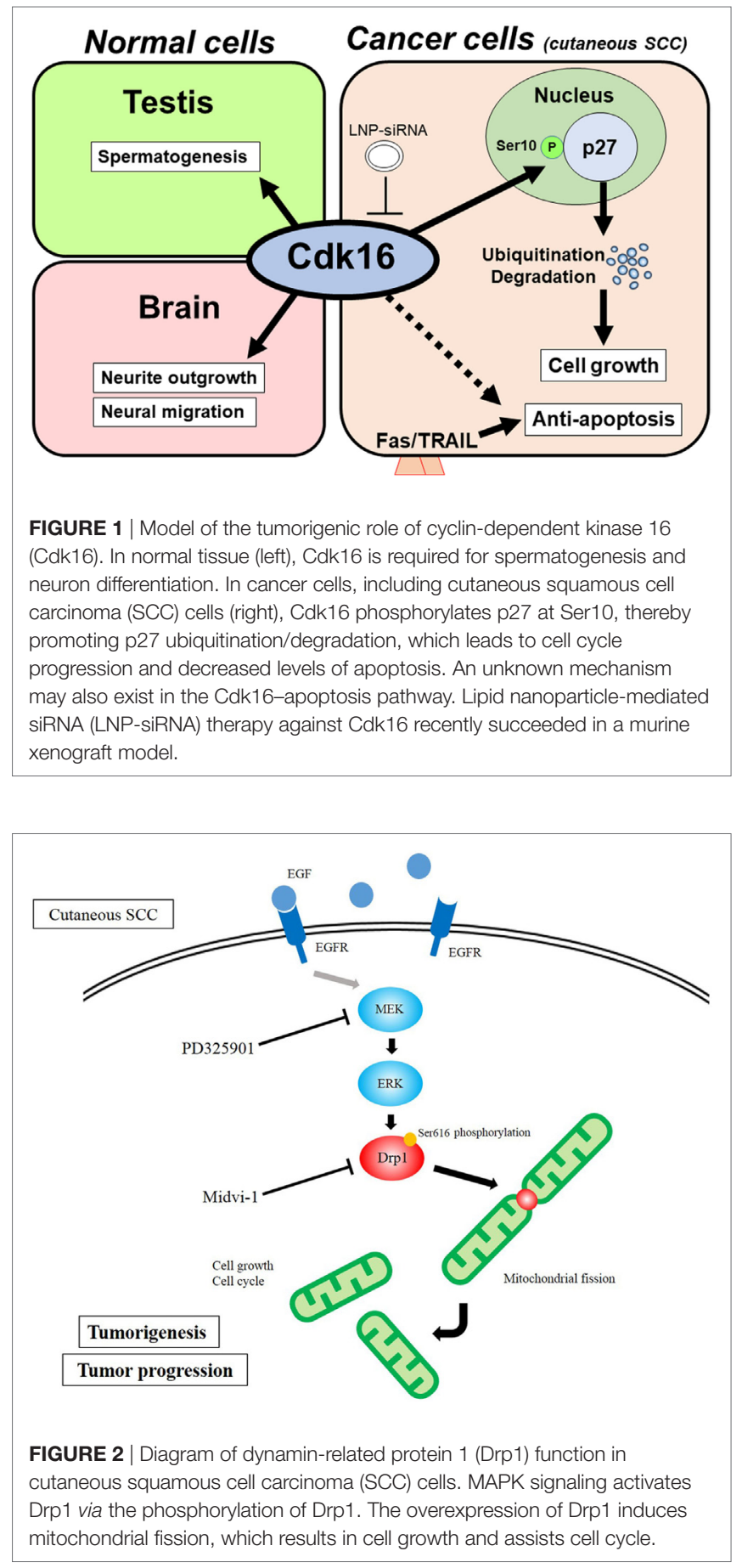

PD325901, inhibited cell proliferation, as well as inhibiting the phosphorylation of ERK1/2 and Drp1 (Ser616). PD325901 also caused the dysregulation of the mitochondrial network. In tumor xenografts of DJM1 SCC cells, the knockdown of Drp1 suppressed tumor growth in vivo. Clinically, the expression levels of Drp1 were higher in cutaneous SCC specimens than in normal epidermis, and those levels correlated positively with advanced clinical stages. Our data reveal a pivotal function for Drp1 in mediating tumor growth, mitochondrial fission, and cell 
cycle in cutaneous SCCs (Figure 2), suggesting that Drp1 could be a novel target for cutaneous SCC therapies.

\section{CONCLUDING REMARKS}

In the past 10 years, novel therapeutic agents for cutaneous SCC have been developed. EGFR inhibitors and immune checkpoint inhibitors have shown particularly promising results. Furthermore, these novel treatments can be used a monotherapies or in combination with radiation; thus dermatologists and oncologists will be able to choose better treatments depending on conditions of the patient and the stage of the disease. Also, novel targeting molecules and inhibitors have been developed.

\section{REFERENCES}

1. Burton KA, Ashack KA, Khachemoune A. Cutaneous squamous cell carcinoma: a review of high-risk and metastatic disease. Am J Clin Dermatol (2016) 17:491-508. doi:10.1007/s40257-016-0207-3

2. Madan V, Lear JT, Szeimies RM. Non-melanoma skin cancer. Lancet (2010) 375:673-85. doi:10.1016/S0140-6736(09)61196-X

3. Stratigos A, Garbe C, Lebbe C, Malvehy J, Marmol V, Pehamberger H, et al. Diagnosis and treatment of invasive squamous cell carcinoma of the skin: European consensus-based interdisciplinary guideline. Eur J Cancer (2015) 51:1989-2007. doi:10.1016/j.ejca.2015.06.110

4. Kopecki Z, Yang GN, Jackson JE, Melville EL, Calley MP, Murrell DF, et al. Cytoskeletal protein flightless I inhibits apoptosis, enhances tumor cell invasion and promotes cutaneous squamous cell carcinoma progression. Oncotarget (2015) 6:36426-40. doi:10.18632/oncotarget.5536

5. Weinberg AS, Ogle CA, Shim EK. Metastatic cutaneous squamous cell carcinoma: an update. Dermatol Surg (2007) 33:885-99. doi:10.1097/00042728200708000-00001

6. Ikegawa S, Saida T, Obayashi H, Sasaki A, Esumi H, Ikeda S, et al. Cisplatin combination chemotherapy in squamous cell carcinoma and adenoid cystic carcinoma of the skin. J Dermatol (1989) 16:227-30. doi:10.1111/ j.1346-8138.1989.tb01254.x

7. Khansur T, Kennedy A. Cisplatin and 5-fluorouracil for advanced locoregional and metastatic squamous cell carcinoma of the skin. Cancer (1991) 67:2030-2. doi:10.1002/1097-0142(19910415)67:8<2030::AID-CNCR2820670803>3.0.CO;2-K

8. Nakamura K, Okuyama R, Saida T, Uhara H. Platinum and anthracycline therapy for advanced cutaneous squamous cell carcinoma. Int J Clin Oncol (2013) 18:506-9. doi:10.1007/s10147-012-0411-y

9. Behshad R, Garcia-Zuazaga J, Bordeaux JS. Systemic treatment of locally advanced nonmetastatic cutaneous squamous cell carcinoma: a review of the literature. Br J Dermatol (2011) 165:1169-77. doi:10.1111/j.1365-2133.2011. 10524.x

10. Lewis CM, Glisson BS, Feng L, Wan F, Tang X, Wistuba II, et al. A phase II study of gefitinib for aggressive cutaneous squamous cell carcinoma of the head and neck. Clin Cancer Res (2012) 18:1435-46. doi:10.1158/1078-0432. CCR-11-1951

11. Maubec E, Petrow P, Scheer-Senyarich I, Duvillard P, Lacroix L, Gelly J, et al. Phase II study of cetuximab as first-line single-drug therapy in patients with unresectable squamous cell carcinoma of the skin. JClin Oncol (2011) 29:3419-26. doi:10.1200/JCO.2010.34.1735

12. Borradori L, Sutton B, Shayesteh P, Daniels GA. Rescue therapy with antiprogrammed cell death protein 1 inhibitors (PD-1) of advanced cutaneous squamous cell carcinoma and basosquamous carcinoma: preliminary experience in 5 cases. Br J Dermatol (2016) 175:1382-6. doi:10.1111/bjd.14642

13. Fujisawa Y, Umebayashi Y, Ichikawa E, Kawachi Y, Otsuka F. Chemoradiation using low-dose cisplatin and 5-fluorouracil in locally advanced squamous cell carcinoma of the skin: a report of two cases. J Am Acad Dermatol (2006) 55:S81-5. doi:10.1016/j.jaad.2005.12.035

14. Reigneau M, Robert C, Routier E, Mamelle G, Moya-Plana A, Tomasic G, et al. Efficacy of neoadjuvant cetuximab alone or with platinum salt for the

\section{AUTHOR CONTRIBUTIONS}

TY and HH designed the study. TY and SK wrote the paper. HH supervised the study.

\section{FUNDING}

This work was supported by JSPS Grants-in-Aid for young scientists (\#15H05998, \#16K1970106), Ichiro Kanehara foundation for the promotion of medical science, the cosmetology research foundation, Ono cancer research foundation, Takeda science foundation, Suhara memorial foundation, geriatric dermatology foundation, and Pias skin research foundation (to TY).

treatment of unresectable advanced nonmetastatic cutaneous squamous cell carcinomas. Br J Dermatol (2015) 173:527-34. doi:10.1111/bjd.13741

15. Preneau S, Rio E, Brocard A, Peuvrel L, Nguyen JM, Quéreux G, et al. Efficacy of cetuximab in the treatment of squamous cell carcinoma. J Dermatolog Treat (2014) 25:424-7. doi:10.3109/09546634.2012.751481

16. Baltaci M, Fritsch P, Weber F, Tzankov A, Sögner P, Derler AM, et al. Treatment with gefitinib (ZD1839) in a patient with advanced cutaneous squamous cell carcinoma. Br J Dermatol (2005) 153:234-6. doi:10.1111/ j.1365-2133.2005.06709.x

17. Kawakami Y, Nakamura K, Nishibu A, Yanagihori H, Kimura H, Yamamoto T. Regression of cutaneous squamous cell carcinoma in a patient with chronic myeloid leukaemiaon imatinib mesylate treatment. Acta Derm Venereol (2008) 88:185-6. doi:10.2340/00015555-0368

18. William WN Jr, Feng L, Ferrarotto R, Ginsberg L, Kies M, Lippman S, et al. Gefitinib for patients with incurable cutaneous squamous cell carcinoma: a single-arm phase II clinical trial. J Am Acad Dermatol (2017) 77:1110-3. doi:10.1016/j.jaad.2017.07.048

19. Ramadan KM, McKenna KE, Morris TC. Clinical response of cutaneous squamous-cell carcinoma to bortezomib given for myeloma. Lancet Oncol (2006) 7:958-9. doi:10.1016/S1470-2045(06)70944-5

20. Shin DM, Glisson BS, Khuri FR, Clifford JL, Clayman G, Benner SE, et al. Phase II and biologic study of interferon alfa, retinoic acid, and cisplatin in advanced squamous skin cancer. J Clin Oncol (2002) 20:364-70. doi:10.1200/JCO.20.2.364

21. Hoff PM, Ansari R, Batist G, Cox J, Kocha W, Kuperminc M, et al. Comparison of oral capecitabine versus intravenous fluorouracil plus leucovorin as firstline treatment in 605 patients with metastatic colorectal cancer: results of a randomized phase III study. J Clin Oncol (2001) 19:2282-92. doi:10.1200/JCO. 2001.19.8.2282

22. Robbins KT, Homma A. Intra-arterial chemotherapy for head and neck cancer: experiences from three continents. Surg Oncol Clin N Am (2008) 17:919-33. doi:10.1016/j.soc.2008.04.015

23. Sheen YT, Lai CS, Sheen YS, Yang SF, Sheen MC. Palmar squamous cell carcinoma successfully treated by intra-arterial infusion chemotherapy. J Am Acad Dermatol (2012) 67:e263-4. doi:10.1016/j.jaad.2012.03.035

24. Argiris A, Harrington KJ, Tahara M, Schulten J, Chomette P, Ferreira Castro A, et al. Evidence-based treatment options in recurrent and/or metastatic squamous cell carcinoma of the head and neck. Front Oncol (2017) 7:72. doi:10.3389/ fonc.2017.00072

25. Bauml J, Seiwert TY, Pfister DG, Worden F, Liu SV, Gilbert J, et al. Pembrolizumab for platinum- and cetuximab-refractory head and neck cancer: results from a single-arm, phase II study. J Clin Oncol (2017) 35:1542-9. doi:10.1200/ JCO.2016.70.1524

26. Degache E, Crochet J, Simon N, Tardieu M, Trabelsi S, Moncourier M, et al. Major response to pembrolizumab in two patients with locally advanced cutaneous squamous cell carcinoma. J Eur Acad Dermatol Venereol (2017). doi:10.1111/jdv.14371

27. Deinlein T, Lax SF, Schwarz T, Giuffrida R, Schmid-Zalaudek K, Zalaudek I. Rapid response of metastatic cutaneous squamous cell carcinoma to pembrolizumab in a patient with xeroderma pigmentosum: case report and review of the literature. Eur J Cancer (2017) 83:99-102. doi:10.1016/j.ejca.2017. 06.022 
28. Stevenson ML, Wang CQ, Abikhair M, Roudiani N, Felsen D, Krueger JG, et al. Expression of programmed cell death ligand in cutaneous squamous cell carcinoma and treatment of locally advanced disease with pembrolizumab. JAMA Dermatol (2017) 153:299-303. doi:10.1001/jamadermatol. 2016.5118

29. Winkler JK, Schneiderbauer R, Bender C, Sedlaczek O, Fröhling S, Penzel R, et al. Anti-programmed cell death-1 therapy in nonmelanoma skin cancer. Br J Dermatol (2017) 176:498-502. doi:10.1111/bjd.14664

30. Guthrie TH Jr, Porubsky ES, Luxenberg MN, Shah KJ, Wurtz KL, Watson PR. Cisplatin-based chemotherapy in advanced basal and squamous cell carcinomas of the skin: results in 28 patients including 13 patients receiving multimodality therapy. J Clin Oncol (1990) 8:342-6. doi:10.1200/JCO.1990.8.2.342

31. Loeffler JS, Larson DA, Clark JR, Weichselbaum RR, Norris CM Jr, Ervin TJ. Treatment of perineural metastasis from squamous carcinoma of the skin with aggressive combination chemotherapy and irradiation. J Surg Oncol (1985) 29:181-3. doi:10.1002/jso.2930290310

32. Postow MA, Callahan MK, Barker CA, Yamada Y, Yuan J, Kitano S, et al. Immunologic correlates of the abscopal effect in a patient with melanoma. N Engl J Med (2012) 366:925-31. doi:10.1056/NEJMoa1112824

33. Wang J, Aldabagh B, Yu J, Arron ST. Role of human papillomavirus in cutaneous squamous cell carcinoma: a meta-analysis. J Am Acad Dermatol (2014) 70:621-9. doi:10.1016/j.jaad.2014.01.857

34. Hasche D, Stephan S, Braspenning-Wesch I, Mikulec J, Niebler M, Gröne HJ, et al. The interplay of UV and cutaneous papillomavirus infection in skin cancer development. PLoS Pathog (2017) 13:e1006723. doi:10.1371/journal.ppat.1006723

35. Biktasova A, Hajek M, Sewell A, Gary C, Bellinger G, Deshpande HA, et al. Demethylation therapy as a targeted treatment for human papillomavirusassociated head and neck cancer. Clin Cancer Res (2017) 23:7276-87. doi:10.1158/ 1078-0432.CCR-17-1438

36. Yu X, Li Z. The role of miRNAs in cutaneous squamous cell carcinoma. J Cell Mol Med (2016) 20:3-9. doi:10.1111/jcmm.12649

37. Lin N, Zhou Y, Lian X, Tu Y. MicroRNA-31 functions as an oncogenic microRNA in cutaneous squamous cell carcinoma cells by targeting RhoTBT1. Oncol Lett (2017) 13:1078-82. doi:10.3892/ol.2017.5554

38. Cheng CJ, Bahal R, Babar IA, Pincus Z, Barrera F, Liu C, et al. MicroRNA silencing for cancer therapy targeted to the tumour microenvironment. Nature (2015) 518:107-10. doi:10.1038/nature13905

39. Turner NC, Ro J, André F, Loi S, Verma S, Iwata H, et al. Palbociclib in hormone-receptor-positive advanced breast cancer. N Engl J Med (2015) 373:209-19. doi:10.1056/NEJMoa1505270

40. Finn RS, Martin M, Rugo HS, Jones S, Im SA, Gelmon K, et al. Palbociclib and letrozole in advanced breast cancer. N Engl J Med (2016) 375:1925-36. doi:10.1056/NEJMoa1607303

41. Cole AR. PCTK proteins: the forgotten brain kinases? Neurosignals (2009) 17:288-97. doi:10.1159/000231895

42. Ou CY, Poon VY, Maeder CI, Watanabe S, Lehrman EK, Fu AK, et al. Two cyclin-dependent kinase pathways are essential for polarized trafficking of presynaptic components. Cell (2010) 141:846-58. doi:10.1016/j.cell.2010.04.011

43. Mikolcevic P, Rainer J, Geley S. Orphan kinases turn eccentric: a new class of cyclin Y-activated, membrane-targeted CDKs. Cell Cycle (2012) 11:3758-68. doi:10.4161/cc.21592

44. Yanagi T, Matsuzawa S. PCTAIRE1/PCTK1/CDK16: a new oncotarget. Cell Cycle (2015) 14:463-4. doi:10.1080/15384101.2015.1006539
45. Yanagi T, Reed JC, Matsuzawa S. PCTAIRE1 regulates p27 stability, apoptosis and tumor growth in malignant melanoma. Oncoscience (2014) 1:624-33. doi:10.18632/oncoscience.86

46. Yanagi T, Krajewska M, Matsuzawa S, Reed JC. PCTAIRE1 phosphorylates p27 and regulates mitosis in cancer cells. Cancer Res (2014) 74:5795-807. doi:10.1158/0008-5472.CAN-14-0872

47. Yanagi T, Hata H, Mizuno E, Kitamura S, Imafuku K, Nakazato S, et al. PCTAIRE1/CDK16/PCTK1 is overexpressed in cutaneous squamous cell carcinoma and regulates p27 stability and cell cycle. J Dermatol Sci (2017) 86:149-57. doi:10.1016/j.jdermsci.2017.02.281

48. Yamaguchi Y, Yanagi T, Imafuku K, Kitamura S, Hata H, Nishihara H, et al. A case of linear basal cell carcinoma: evaluation of proliferative activity by immunohistochemical staining of PCTAIRE1 and p27. J Eur Acad Dermatol Venereol (2017) 31(8):e359-62. doi:10.1111/jdv.14159

49. Yanagi T, Shi R, Aza-Blanc P, Reed JC, Matsuzawa S. PCTAIRE1-knockdown sensitizes cancer cells to TNF family cytokines. PLoS One (2015) 10:e0119404. doi:10.1371/journal.pone.0119404

50. Yanagi T, Tachikawa K, Wilkie-Grantham R, Hishiki A, Nagai KO, Toyonaga E, et al. Lipid nanoparticle-mediated siRNA transfer against PCTAIRE1/PCTK1/ Cdk16 inhibits in vivo cancer growth. Mol Ther Nucleic Acids (2016) 5:e327. doi:10.1038/mtna.2016.40

51. Kitamura S, Yanagi T, Imafuku K, Hata H, Abe R, Shimizu H. Drp1 regulates mitochondrial morphology and cell proliferation in cutaneous squamous cell carcinoma. J Dermatol Sci (2017) 88:298-307. doi:10.1016/j. jdermsci.2017.08.004

52. Wieder SY, Serasinghe MN, Sung JC, Choi DC, Birqe MB, Yao JL, et al. Activation of the mitochondrial fragmentation protein DRP1 correlates with BRAF(V600E) melanoma. J Invest Dermatol (2015) 135:2544-7. doi:10.1038/ jid.2015.196

53. Qian W, Choi S, Gibson GA, Watkins SC, Bakkenist CJ, Van Houten B. Mitochondrial hyperfusion induced by loss of the fission protein Drp1 causes ATM-dependent G2/M arrest and aneuploidy through DNA replication stress. J Cell Sci (2012) 125:5747-57. doi:10.1242/jcs.109769

54. Zhao J, Zhang J, Yu M, Xie Y, Huang Y, Wolff DW, et al. Mitochondrial dynamics regulates migration and invasion of breast cancer cells. Oncogene (2013) 32:4814-24. doi:10.1038/onc.2012.494

55. Chiang YY, Chen SL, Hsiao YT, Huang CH, Lin TY, Chiang IP, et al. Nuclear expression of dynamin-related protein 1 in lung adenocarcinomas. Mod Pathol (2009) 22:1139-50. doi:10.1038/modpathol.2009.83

56. Xie W, Wu Q, Horbinski CM, Flavahan WA, Yang K, Zhou W, et al. Mitochondrial control by DRP1 in brain tumor initiating cells. Nat Neurosci (2015) 18:501-10. doi:10.1038/nn.3960

Conflict of Interest Statement: The authors declare that the research was conducted in the absence of any commercial or financial relationships that could be construed as a potential conflict of interest.

Copyright (C) 2018 Yanagi, Kitamura and Hata. This is an open-access article distributed under the terms of the Creative Commons Attribution License (CC BY). The use, distribution or reproduction in other forums is permitted, provided the original author(s) and the copyright owner are credited and that the original publication in this journal is cited, in accordance with accepted academic practice. No use, distribution or reproduction is permitted which does not comply with these terms. 